\title{
STRATEGI PENGEMBANGAN BISNIS PADA INDUSTRI OTOMOTIF
}

\author{
BUSINESS DEVELOPMENT STRATEGY IN THE AUTOMOTIVE INDUSTRY
}

\author{
Titis Wicaksono*), Rizal Syarief*), dan Siti Jahroh*) \\ *) Sekolah Bisnis, IPB University \\ Jl. Pajajaran Bogor 16151, Indonesia
}

\begin{abstract}
PT. XYZ is part of the steel industry that focuses on the automotive sector which is very possible to increase business capacity. The decline in profit ratio in the last four years has triggered the development of a business model. The research aims to (1) identify the business model canvas of PT. XYZ, (2) analysis of the influence of internal and external factors for the company, and (3) create a business development strategy. The research was conducted using descriptive methods utilizing business model canvas, SWOT, and Blue Ocean Strategy analysis tools. Research analysis techniques based on primary and secondary data collected in February 2019 - June 2019 through the method of observation, interviews, questionnaires, and literature studies. Respondents were selected by purposive sampling technique, which is the technique for determining respondents who are considered experts and understand the situation of PT. XYZ both internal and external. The business development strategy is carried out through the development of the company's current business model canvas with a combination of blue ocean strategy perspectives based on the direction of the company's business development, evaluation of business model elements, environmental analysis. According to the research results obtained two business model development strategies where the first strategy is the improvement of cost structure elements by reducing the purchase of imported raw materials and creating components of local suppliers in the key partner elements to reduce the cost of purchasing materials. The second strategy is to improve the elements of key activities by develop business operating sistems and develop customer segments, which targets companies that manufacture two-wheeled vehicle components.
\end{abstract}

Keywords: business model canvas, blue ocean strategy, automotive, SWOT, steel

Abstrak: PT. XYZ merupakan bagian dari industri baja yang fokus pada bidang otomotif yang sangat memungkinkan untuk meningkatkan kapasitas bisnis. Penurunan rasio laba dalam empat tahun terakhir menjadi pemicu untuk dilakukan pengembangan model bisnis untuk memperbaiki situasi bisnisnya. Penelitian bertujuan untuk (1) identifikasi business model canvas PT. XYZ, (2) analisis pengaruh faktor internal dan eksternal bagi perusahaan, dan (3) membuat strategi pengembangan bisnis. Penelitian dilakukan dengan metode deskriptif dengan alat analisis business model canvas, SWOT, and Blue Ocean Strategy. Teknik analisis penelitian berdasarkan pada data primer dan data sekunder yang dikumpulkan pada periode Februari 2019 - Juni 2019 melalui metode observasi, wawancara, kuesioner, dan studi literatur. Pemilihan responden dilakukan dengan teknik secara sengaja (purposive sampling) yaitu teknik penentuan responden yang dianggap ahli dan paham mengenai situasi PT. XYZ baik internal maupun eksternal. Strategi pengembangan bisnis dilakukan melalui pengembangan business model canvas perusahaan saat ini dengan kombinasi perspektif blue ocean strategy berdasarkan arah pengembangan bisnis perusahaan, evaluasi elemen model bisnis, analisis lingkungan internal dan eksternal. Dari hasil penelitian didapatkan dua strategi pengembangan model bisnis dimana strategi pertama adalah perbaikan elemen cost structure yaitu dengan mengurangi pembelian bahan baku secara impor dan menciptakan komponen pemasok lokal pada elemen key partners guna menurunkan biaya pembelian material. Strategi kedua adalah perbaikan elemen key activities yaitu dengan pengembangan sistem operasi bisnis dan pengembangan customer segments yaitu menyasar perusahaan pembuat komponen kendaraan roda dua.

Kata kunci: kanvas model bisnis,strategi samudera biru, otomotif, SWOT, baja

\footnotetext{
${ }^{1}$ Alamat korespondensi:

Email: titispetrucci@gmail.com
} 


\section{PENDAHULUAN}

Visi pembangunan Industri Nasional sebagaimana yang tercantum dalam Peraturan Presiden Nomor 28 Tahun 2008 tentang Kebijakan Industri Nasional adalah Indonesia menjadi Negara Industri Tangguh pada tahun 2025. Industri baja merupakan bagian dari industri manufaktur yang diharapkan menjadi basis pengembangan industri andalan. Hasni dan Manulang (2011) menjelaskan bahwa konsumsi baja suatu negara merupakan salah satu indikator kemajuan negara.

Data South East Asia Iron and Steel Institue (SEAISI, 2017) menunjukkan bahwa perkiraan konsumsi baja Indonesia mencapai $55 \mathrm{~kg} /$ kapita pada tahun 2018 . Angka tersebut adalah yang terkecil jika dibandingkan konsumsi negara Asia Tenggara lainnya seperti Singapura 486 kg/kapita, Malaysia 294 kg/kapita, Thailand $266 \mathrm{~kg} / \mathrm{kapita}$, Vietnam $238 \mathrm{~kg} / \mathrm{kapita}$, dan Filipina $96 \mathrm{~kg} / \mathrm{kapita}$ di tahun yang sama. Konsumsi baja nasional sejak 3 tahun terakhir mengalami tren positif. SEAISI mencatat konsumsi baja Indonesia sebesar 11,4 juta ton pada tahun 2015 dan mengalami peningkatan pada tahun 2016 menjadi 12,7 juta ton. Peningkatan konsumsi kembali terjadi pada tahun 2017 menjadi 13,4 juta ton. Tingkat konsumsi baja per kapita merupakan indikator yang menunjukkan tingkat kemajuan ekonomi suatu negara, karena pertumbuhan ekonomi didorong oleh kegiatan investasi dan pembangunan infrastruktur di segala bidang, di mana baja berperan sebagai penghelanya (Prasetyo, 2010).

Pertumbuhan konsumsi baja diharapkan berbanding lurus dengan Rencana Induk Pembangunan Industri Nasional 2015-2035 (RIPIN) dimana pemerintah menargetkan peningkatan konsumsi baja nasional sebesar 20 juta ton per tahun pada tahun 2020. Angka tersebut diharapkan meningkat menjadi 28 juta ton pada tahun 2024. Dan pada tahun 2035, pemerintah menargetkan konsumsi baja sebesar 40 juta ton. Indonesian Iron and Steel Industri Association (IISIA) menyebutkan bahwa pada tahun 2017, konsumsi baja terbesar didominasi oleh sektor konstruksi sebesar $78 \%$. Diikuti sektor otomotif sebesar $8 \%$ dan sektor migas sebesar 7\% dan 7\% sisanya untuk bidang lainlain. Guna menunjang industri baja, Indonesia memiliki sumber daya alam yaitu besi laterit, besi primer, pasir besi. Jumlah sumber daya alam diperkirakan sebanyak 11,349 juta ton dan jumlah cadangan diperkirakan sebanyak 3,089 juta ton. Berdasarkan hal itu, industri baja memiliki potensi yang sangat besar. Alam Indonesia memiliki potensi endapan biji besi yang cukup besar, baik dalam bentuk bijih besi primer, sekunder maupun laterit (Ishlah, 2009).

Uraian tersebut merupakan peluang bagi PT. XYZ sebagai perusahaan yang fokus pada material baja untuk mengembangkan bisnisnya.PT.XYZ merupakan bagian dari industri baja yang fokus pada bidang otomotif yang sangat memungkinkan untuk meningkatkan kapasitas bisnis. Namun, kondisi penurunan rasio laba dalam 4 tahun terakhir menjadi hal penting yang harus diperbaiki meskipun terjadi peningkatan nilai penjualan. Peningkatan nilai penjualan memberikan indikasi bahwa adanya peningkatan beban aktivitas kerja. Sistem operasi bisnis yang belum memadai pun memberikan dampak peningkatan beban kerja sehingga menyebabkan peningkatan jam kerja karyawan yang berdampak pada peningkatan beban gaji karyawan. Pembelian bahan baku material yang diperoleh melalui pemasok luar negeri juga memberikan kontribusi meningkatnya beban pembelian karena harga material dan biaya transportasi yang tinggi. PT. XYZ memiliki beberapa produk baja yaitu baja karbon (carbon steel) dan baja anti karat (stainless steel) dalam bentuk gulungan baja dan pelat atau lembaran baja. PT. XYZ melakukan pembelian melalui pemasok dari luar negeri seperti Cina, Korea, dan Jepang. Hal ini didasari atas pertimbangan spesifikasi tertentu untuk pemenuhan kebutuhan industri otomotif yang mengalami pertumbuhan yang positif dari waktu ke waktu. PT. XYZ memiliki pelanggan yang tersebar di area Bogor, Bekasi, Cibitung, Cikarang, Karawang hingga Cikampek dan Surabaya.

Telah banyak penelitian yang dilakukan tentang pengembangan strategi bisnis seperti Manalu (2018) dengan menggunakan SWOT dan QSPM. Penelitian serupa juga dilakukan Zakaria et al. (2018), Yoga et al. (2016), Dewi et al. (2018), Auguar et al. (2017), dan Puryani et al. (2019) dengan menggunakan SWOT dan QSPM untuk menentukan strategi yang tepat untuk pengembangan usaha. Bahkan Tarigan et al. (2019) menggunakan kombinasi BCG, QSPM, dan AHP untuk mengembangkan strategi usaha. Namun Boedianto dan Harjanti (2015) serta Fathurohman (2018) melakukan penelitian dengan menggunakan kanvas model bisnis. Selain itu, Ati et al. (2019) menggunakan kanvas model bisnis untuk mengembangkan strategi usaha lembaga swadaya masyarakat nirlaba. 
Pada dasarnya setiap perusahaan memiliki model bisnis, baik hal tersebut terlihat atau tidak (Teece, 2010). Tjaturpriono (2010) menjelaskan serupa bahwa pada dasarnya semua organisasi mempunyai model bisnis, tetapi apakah model bisnis tersebut sesuai dengan lanskap bisnisnya. Persaingan bisnis yang ketat mendorong perusahaan agar mampu bertahan. Inovasi dalam model bisnis sangat ditekankan sebagai jalur menuju persaingan dan pertumbuhan (Giesen et al. 2007) karena adanya hubungan positif antara model bisnis dan kinerja perusahaan (Brandenburger dan Nalebuff, 1995; Brandenburger dan Stuart, 1996). Model bisnis adalah sebuah rumusan pendapatan, sistem bisnis dan sistem pembelajaran perusahaan (Baden-Fuller dan Morgan, 2010). Model bisnis adalah perwujudan dari logika inti dasar dari perusahaan dan pilihan strategis untuk menciptakan dan menangkap nilai dari sebuah jaringan nilai (Shafera et al. 2005). Peluang baru ditawarkan untuk mengeksplorasi penting dan relevansi pendekatan yang dinamis dan digerakkan oleh desain untuk penciptaan model bisnis yang inovatif (Wrigley dan Straker, 2016). Inovasi model bisnis mampu menciptakan pasar baru yang memungkinkan untuk memanfaatkan peluang baru (Amit dan Zott, 2012). Stefan dan Richard (2014) menjelaskan bahwa model bisnis adalah sebuah sistem dari sumber daya dan aktivitas yang menciptakan nilai yang sangat bermanfaat untuk pelanggan serta penjualan dari nilai ini akan menghasilkan uang bagi perusahaan. Dari definisi model bisnis yang sudah diuraikan sebelumnya, Stefan dan Richard (2014) pun menjelaskan bahwa konsep bisnis model yang paling kompleks adalah kanvas model bisnis. Model bisnis ini menggambarkan tidak hanya ekonomi dan bisnis proses, tetapi bagaimana menciptakan nilai perusahaan. Keuntungan lain dari konsep bisnis model kanvas adalah terskema dan memiliki visualisasi yang universal, serta dapat menjelaskan proses hubungan dari sembilan blok di dalamnya. Penelitian ini dilakukan dengan tujuan untuk membuat strategi pengembangan bisnis dengan pendekatan business model canvas dengan kombinasi perspektif blue ocean strategy berdasarkan arah pengembangan bisnis perusahaan, evaluasi elemen model bisnis, analisis lingkungan internal dan eksternal.

\section{METODE PENELITIAN}

Lokasi penelitian dilakukan di PT XYZ di daerah Jawa Barat. Kesediaan pihak perusahaan untuk menjadi objek penelitian merupakan alasan penentuan lokasi penelitian. Waktu penelitian dilakukan dalam kurun waktu lima bulan dimulai bulan Februari 2019 hingga Juni 2019. Data acuan dalam penelitian adalah data primer dan data sekunder. Data primer didapatkan melalui observasi, wawancara, dan pengisian kuesioner dengan responden yang dipilih secara sengaja yang memiliki kriteria profesional yang mengetahui kondisi usaha PT. XYZ. Data sekunder yang digunakan merupakan data yang tersedia yang berfungsi untuk mendukung penelitian yang berasal dari pihak perusahaan dan pihak lain serta studi literatur berupa data konsumsi baja, penjualan baja, beban penjualan, mesin produksi, varian produk, serta informasi pelanggan dan pemasok, serta penelitian terdahulu.

Hipotesis penelitian adalah faktor internal dan eksternal serta evaluasi model bisnis yang sudah berjalan dengan mengacu pada faktor kekuatan, kelemahan, peluang, serta ancaman, mampu menghasilkan model bisnis baru untuk memperbaiki kondisi bisnis perusahaan. Gambar 1 menjelaskan kerangka penelitian yang diawali pemetaan model bisnis yang sudah berjalan dengan pendekatan kanvas model bisnis. Langkah selanjutnya identifikasi faktor internal dan eksternal untuk mengetahui faktor-faktor yang berpengaruh terhadap bisnis perusahaan. Langkah berikutnya evaluasi model bisnis yang sudah berjalan dengan menggunakan analisis SWOT untuk mengetahui elemen model bisnis yang akan diperbaiki dengan mengacu pada langkah kerja blue ocean strategy dan kebijakan pengembangan bisnis dari perusahaan.

\section{HASIL}

\section{Identifikasi Model Bisnis PT. XYZ}

Gambar 2 merupakan pemetaan model bisnis yang sudah berjalan. Pada blok customer segments, PT. $\mathrm{XYZ}$ memiliki segmen pelanggan yang termasuk dalam kategori pasar ceruk dimana pelanggan memiliki kebutuhan yang lebih spesifik baik dalam negeri maupun luar negeri. Terkait bahasan tersebut, operasi bisnis yang dilakukan oleh PT. XYZ bersifat Business to Business (B2B). 


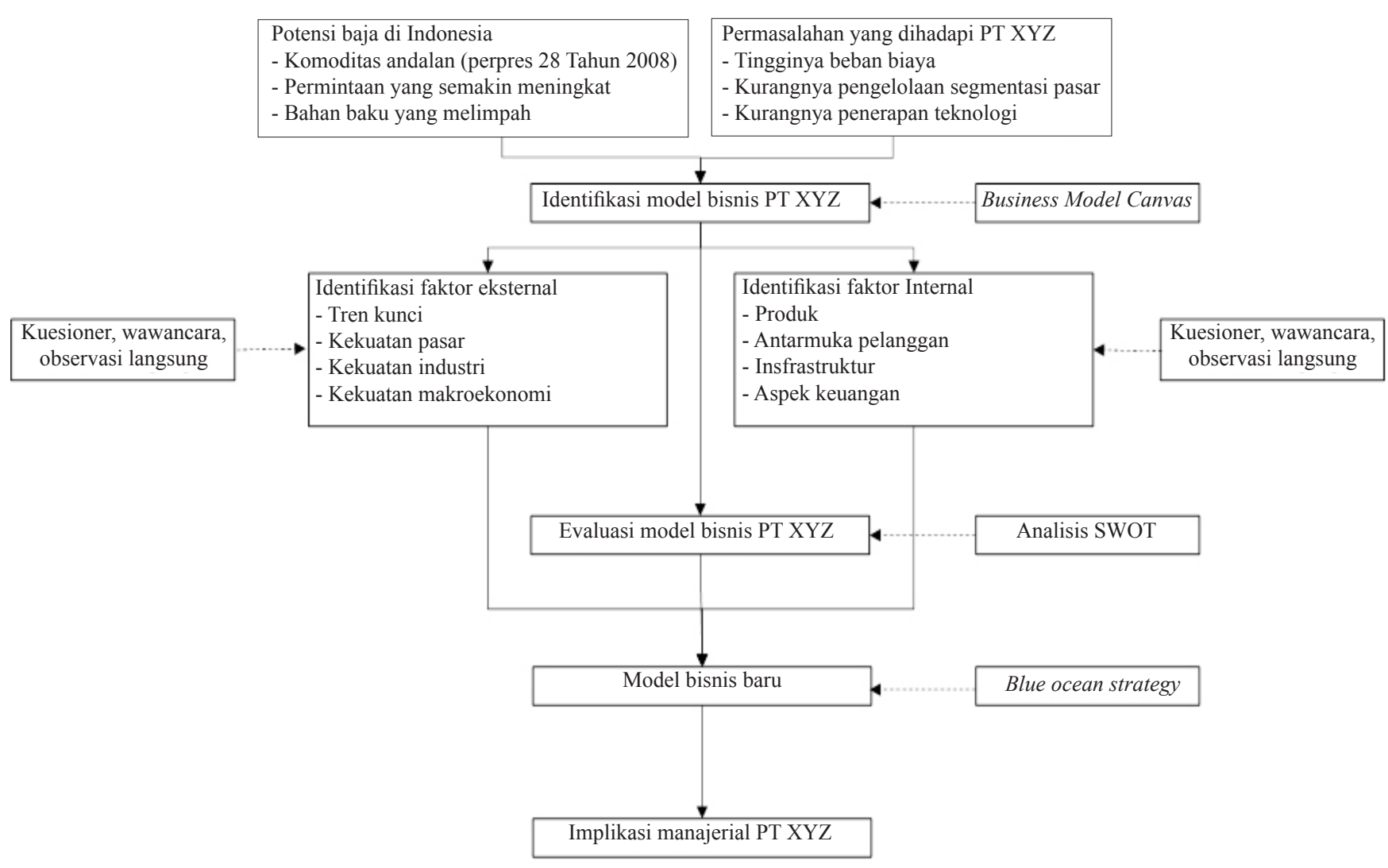

Gambar 1. Kerangka pemikiran penelitian

\begin{tabular}{|c|c|c|c|c|}
\hline \multirow[t]{2}{*}{$\begin{array}{l}\text { Key Partners } \\
\text { - Pemasok luar negeri } \\
\text { - Jasa pengiriman }\end{array}$} & $\begin{array}{l}\text { Key Activities } \\
\text { - Customer retention } \\
\text { - Aktivitas penjualan } \\
\text { - Produksi } \\
\text { - Manajemen } \\
\text { persediaan }\end{array}$ & \multirow[t]{2}{*}{$\begin{array}{l}\text { Value propositions } \\
\text { - Kustomisasi ukuran } \\
\text { produk } \\
\text { - Pengiriman tepat } \\
\text { waktu } \\
\text { - Kedekatan jarak }\end{array}$} & $\begin{array}{l}\text { Customer } \\
\text { Relationships } \\
\text { - Layanan personal } \\
\text { berdedikasi }\end{array}$ & \multirow[t]{2}{*}{$\begin{array}{l}\text { Customer Segments } \\
\text { - Perusahaan pembuat } \\
\text { komponen kendaraan } \\
\text { roda empat }\end{array}$} \\
\hline & $\begin{array}{l}\text { Key Resources } \\
\text { - SDM } \\
\text { - Fasilitas produksi } \\
\text { - Jaringan }\end{array}$ & & $\begin{array}{l}\text { Channels } \\
\text { - Tenaga penjualan } \\
\text { - Kantor perusahaan }\end{array}$ & \\
\hline \multicolumn{2}{|c|}{$\begin{array}{l}\text { Cost Structure } \\
\text { - Biaya transportasi } \\
\text { - Biaya pembelian material } \\
\text { - Biaya gaji SDM } \\
\text { - Biaya proses produksi }\end{array}$} & & $\begin{array}{l}\text { Revenue Streams } \\
\text { - Penjualan produk }\end{array}$ & \\
\hline
\end{tabular}

Gambar 2. Pemetaan model bisnis PT. XYZ 
PT. XYZ merupakan penyedia bahan baku baja dengan kustomisasi ukuran. Hal ini memungkinkan bagi setiap pelanggan untuk menentukan ukuran produk secara bebas yang akan disesuaikan dengan mesin produksi pada masing-masing pelanggan. PT. XYZ memiliki performa pengiriman yang tepat waktu karena ditunjang kapasitas produksi yang besar dan cepat. PT. XYZ memiliki jarak yang relatif dekat dengan para pelanggan. Faktor tersebut memberikan peluang bagi pelanggan untuk memiliki tingkat efisiensi proses yang baik. Uraian tersebut dapat terlihat pada pada blok value propositions. Pada blok channels, perusahaan menerapkan direct channel atau saluran langsung. Perusahaan melakukan proses transaksi penjualan produk secara langsung kepada pelanggan.

PT. XYZ menggunakan tenaga penjualan dan kantor perusahaanuntukmelakukantransaksipenjualanproduk. Tenaga penjualan secara berkala melakukan kunjungan kepada pelanggan untuk membangun hubungan yang lebih baik dengan melakukan komunikasi lebih mendalam terkait kebutuhan pelanggan. Pada blok customer relationships, perusahaan menjalin hubungan baik yang bersifat dedicated personal assistance (bantuan personal yang berdedikasi). Pola hubungan ini didapatkan berdasarkan interaksi antar individu. Pada blok revenue streams, pendapatan PT. XYZ diperoleh melalui penjualan asset (asset sale), yaitu penjualan baja.

Pada blok key activities, aktivitas PT. XYZ terbagi menjadi dua yaitu commercial dan operational. Aktivitas commercial meliputi penjualan dan customer retention. Aktivitas operational meliputi produksi dan manajemen persediaan. Pada blok key resources, PT. $\mathrm{XYZ}$ memiliki jaringan kerjasama yang baik dengan key partners. Fasilitas mesin produksi juga menjadi salah satu key resources seperti mesin slitter dan leveler serta Sumber Daya Manusia (SDM) yang direkrut melalui proses perekrutan dengan kualifikasi tertentu dan diberikan pelatihan yang baik sehingga SDM memiliki kemampuan yang sesuai dengan kebutuhan operasi bisnis PT. XYZ. Pada blok key partners, overseas supplier merupakan mitra kunci dalam hal pengadaan bahan baku. Perusahaan jasa pengiriman juga merupakan mitra kunci bagi PT. XYZ karena memiliki fungsi yang sangat penting untuk pengiriman bahan baku kepada pelanggan dengan tepat waktu. Pada blok cost structure, struktur biaya pada bisnis PT. XYZ terdiri dari biaya tetap dan biaya tidak tetap. Struktur biaya tetap adalah gaji karyawan. Struktur biaya tidak tetap adalah biaya pembelian bahan baku, biaya transportasi, dan biaya produksi.

\section{Analisis Lingkungan Internal}

Untuk memperoleh pemahaman yang baik terkait lingkungan bisnis yang dapat dikendalikan oleh perusahaan, maka diperlukan analisis lingkungan internal dari perusahaan. Menggali berbagai informasi aspek lingkungan internal merupakan bagian dari analisis yang tidak terpisahkan dari bisnis PT. XYZ. Aspek lingkungan internal yaitu meliputi product, customer interface, Infrastructure management dan Financial aspect (Osterwalder dan Pigneur, 2010).

\section{Product}

Faktor-faktor yang memengaruhi produk PT. XYZ meliputi kualitas, kuantitas, bahan baku, proses produksi dan sumber daya manusia. Penilaian yang sangat tinggi diberikan pada aspek kualitas, bahan baku, proses produksi dan sumber daya manusia. Hal ini berarti bahwa kualitas merupakan aspek yang diutamakan oleh perusahaan karena akan memengaruhi keputusan pelanggan untuk membeli produk. Pelatihan yang secara berkala dilakukan diharapkan mampu meningkatkan kemampuan dan kualitas sumber daya manusia sehingga operasi bisnis PT. XYZ dapat dijalankan dengan baik dan sesuai dengan harapan pelanggan.

\section{Customer interface}

Faktor yang memengaruhi customer interface meliputi jarak perusahaan dengan pelanggan, kedekatan perusahaan dengan pelanggan, dan informasi media. Jarak dan kedekatan hubungan perusahaan dengan pelanggan merupakan faktor yang sangat memengaruhi bagi bisnis PT. XYZ. Jarak menimbulkan pertimbangan tersendiri bagi pelanggan karena akan berpengaruh langsung terhadap efisiensi waktu pasok produk. Kedekatan hubungan juga menjadi faktor penting bagi bisnis PT. XYZ. Hubungan yang intensif terkait hal bisnis merupakan hal yang dilakukan dalam rangka membangun keberlanjutan bisnis. Selain itu, hubungan yang intensif mampu memberikan informasi lebih lengkap terkait kebutuhan pelanggan. Faktor berikutnya adalah informasi media yang mendapatkan penilaian penting. Media mampu memberikan informasi terkait perusahaan dengan efektif. 


\section{Infrastructure management}

Dalam operasional bisnis PT. XYZ, keterampilan sumber daya manusia menjadi sangat penting mengingat banyaknya jumlah data yang harus diolah dengan bermacam perbedaan format data baik yang berasal dari pelanggan maupun pemasok. Faktor terpenting berikutnya adalah motivasi kerja dan sistem imbalan yang dinilai sangat terkait yang mampu memberikan dorongan agar karyawan menjadi lebih semangat dalam bekerja. Jenis pekerjaan yang membutuhkan konsentrasi dan ketepatan merupakan faktor yang dianggap menjadi kendala bagi karyawan untuk mempertahankan semangat kerja. Melalui pendekatan finansial, PT XYZ memberikan beberapa tunjangan bagi karyawan seperti bantuan pinjaman untuk keperluan yang mendesak bagi karyawan. Faktor berikutnya yang dinilai penting adalah jumlah SDM. Bagi PT. XYZ, jumlah SDM merupakan faktor yang harus dipertimbangkan dengan akurat sehingga jumlah SDM akan sesuai dengan kebutuhan pekerjaan. Hal tersebut akan berdampak pada efisiensi biaya yang dikeluarkan perusahaan.

\section{Financial aspect}

Hal terpenting yang meliputi financial aspect bagi PT. $\mathrm{XYZ}$ adalah hubungan yang baik dengan penanam modal. Hubungan dengan penanam modal harus dibangun dengan baik karena merupakan salah satu cara dalam mendapatkan kepercayaan dari penanam modal. Faktor terpenting lainnya adalah harga jual bahan baku. hal tersebut menjadi sangat penting karena terkait dengan aktivitas penjualan. PT. XYZ senantiasa berusaha menentukan harga jual yang kompetitif dengan kualitas yang terjamin sehingga operasional jual dan beli dengan pelanggan akan tetap terjaga. Faktor lainnya yang meliputi financial aspect adalah pengelolaan keuangan, kemampuan perusahaan memupuk modal, upaya untuk memperoleh modal tambahan, struktur modal kerja, dan sistem akunting yang handal merupakan faktor yang dinilai biasa oleh PT. XYZ. Hal ini terkait dengan aktivitas utama PT. XYZ dalam hal penjualan bahan baku baja sehingga faktor-faktor tersebut dinilai tidak diperlukan dilakukan hal besar pada faktor tersebut.

\section{Analisis Lingkungan Eksternal}

Identifikasi lingkungan eksternal dilakukan guna mengetahui dan memahami aspek lingkungan yang tidak mampu dikendalikan perusahaan. Identifikasi aspek lingkungan eksternal dilakukan dengan memetakan empat area utama lingkungan yang meliputi tren kunci, kekuatan pasar, kekuatan industri, kekuatan ekonomi makro (Osterwalder dan Pigneur, 2010).

\section{Kekuatan pasar}

Faktor eksternal yang paling mempengaruhi model bisnis PT. XYZ adalah kekuatan pasar (29,13\%). Pangsa pasar merupakan faktor yang digunakan sebagai indicator untuk penentuan strategi bisnis (Bamford et al. 2000). Hal yang menjadi penilaian pada aspek kekuatan pasar adalah isu-isu pasar, kebutuhan pasar, permintaan pasar, biaya perpindahan dan daya pikat pendapatan. Daya pikat pendapatan memiliki pengaruh paling besar terhadap bisnis PT. XYZ. Hal ini disebabkan beberapa variabel yaitu harga jual produk olahan baja dan kemudahan menjual produk. Variabel tersebut sangat berpengaruh pada aktivitas penjualan dan pendapatan pelaku usaha dimana semakin pendapatan akan bertambah tinggi seiring meningkatnya harga.

\section{Kekuatan industri}

Faktor eksternal berikutnya yang paling memengaruhi model bisnis PT. XYZ adalah kekuatan industri (24,69\%). Variabel pemain baru merupakan variabel yang paling berpengaruh terhadap model bisnis PT. XYZ. Diikuti variabel yang berpengaruh berikutnya adalah pemasok dan pelaku rantai nilai lainnya, produk dan jasa pengganti, stakeholder, dan pesaing. Pesaing merupakan variabel yang paling berpengaruh terhadap model bisnis PT. XYZ. Variabel ini dipengaruhi oleh jumlah pesaing, tingkat pertumbuhan industri, biaya tetap, biaya peralihan, diferensiasai produk, tambahan kapasitas produksi, karakteristik pesaing, hambatan keluar industri, tingkat taruhan strategis perusahaan agar sukses di dalam industri. Bidang otomotif sebagai segmen pasar bagi PT. XYZ mengalami perkembangan yang sangat pesat. Hal ini ditandai dengan masuknya pemain baru yang pada akhirnya memicu persaingan. 


\section{Tren kunci}

Faktor eksternal berikutnya yang paling mempengaruhi model bisnis PT. XYZ adalah tren kunci $(23,61 \%)$. Analisis masa depan lingkungan industri (industry foresight) atau analisis tren kunci meliputi tren teknologi, tren regulasi dan politik, tren masyarakat dan budaya, dan tren sosio ekonomi. Tren masyarakat dan budaya serta teknologi menjadi hal yang paling berpengaruh pada analisis tren kunci. Sikap dan gaya hidup masyarakat, pendidikan, pola konsumsi, dan populasimerupakanpemicuutamaperubahankebutuhan khususnya kebutuhan akan media transportasi yang lebih baik dan cepat

\section{Kekuatan ekonomi makro}

Faktor eksternal berikutnya yang paling mempengaruhi model bisnis PT. XYZ adalah tren kunci $(22,58 \%)$. Analisis kekuatan ekonomi makro merupakan faktor dengan pengaruh yang paling kecil. Bisnis baja saat ini lebih dipengaruhi oleh kondisi pasar global. Penurunan nilai rupiah terhadap dolar merupakan isu utama dalam bisnis baja dimana sebagian besar kuantitas masih didapatkan melalui impor.

\section{Evaluasi Model Bisnis}

Evaluasi model bisnis dilakukan dengan menggunakan analisis SWOT dengan memberikan nilai (scoring) pada 9 elemen model bisnis kanvas yang kemudian dikalkulasi secara manual sehingga didapatkan hasil evaluasi pada Gambar 3. Kombinasi kekuatan dan kelemahan dilakukan karena adanya kondisi pertanyaan kuesioner yang sama namun memiliki makna berlawan. Rangkuti (2006) menjelaskan bahwa analisis SWOT adalah identifikasi berbagai faktor secara sistematis untuk merumuskan strategi perusahaan. Analisis ini didasarkan pada logika yang dapat memaksimalkan kekuatan (strengths), peluang (opportunities). Namun, secara bersamaan dapat meminimalkan kelemahan (weakness) dan ancaman (threats).

\section{Customer segments}

Gambar 3 memperlihatkan hasil penilaian pada elemen customer segments yaitu kekuatan/kelemahan 3,0 (sedang), peluang 4,33 (tinggi), dan ancaman 1,5 (rendah). Kekuatan pada segmen pelanggan dipengaruhi oleh kemampuan dalam segmentasi pelanggan. Penilaian peluang pada segmen pelanggan dipengaruhi oleh kemampuan dalam mendapatkan penghasilan dari kondisi pasar yang berkembang dan melayani pelanggan dengan lebih baik dengan segmentasi yang lebih baik. Ancaman pada elemen ini dipengaruhi oleh pesaing yang mengancam pangsa pasar serta kemungkinan pelanggan yang akan pergi.

\section{Value propositions}

Pada elemen proposisi nilai dihasilkan penilaian kekuatan/kelemahan 4,5 (sangat tinggi), peluang 4,0 (tinggi), dan ancaman 1,0 (sangat rendah). Kekuatan pada proposisi nilai dipengaruhi oleh kemampuan PT. XYZ dalam membangun nilai produk dan layanan yang sesuai dengan kebutuhan palanggan serta memiliki jaringan yang kuat sehingga menghasilkan tingkat kepuasan pelanggan yang tinggi. Peluang dipengaruhi oleh perubahan produk menjadi layanan serta mengintegrasikan kedua hal tersebut untuk menghasilkan pendapatan berulang. Penawaran produk dan layanan pengganti serta harga yang lebih baik merupakan ancaman dengan tingkat yang sangat rendah.

\section{Channels}

Pada elemen saluran dihasilkan penilaian kekuatan/ kelemahan 1,71 (rendah), peluang 3,8 (tinggi), dan ancaman 1,0 (sangat rendah). Kekuatan saluran terletak pada efektifitas dan efisiensi. Peluang untuk mengintegrasikan saluran juga harus diperhatikan agar lebih efisien dan efektif agar selaras dengan segmen pelanggan sehingga dimungkinkan untuk mendapatkan pelanggan baru dan meningkatkan margin. Saluran pesaing masih sangat kecil berpengaruh mengancam saluran PT. XYZ.

\section{Customer Relationships}

Hasil penilaian pada elemen hubungan pelanggan adalah kekuatan/kelemahan 3,75 (tinggi), peluang 3,5 (tinggi), dan ancaman 3,0 (sedang). Kekuatan hubungan pelanggan dipengaruhi oleh hubungan yang selaras dan kuat sehingga menghasilkan hubungan yang mengikat dalam rangka mempertahankan eksistensi pelanggan. Peluang yang perlu diperhatikan adalah lebih memperkuat hubungan dengan pelanggan dan meningkatkan biaya perpindahan. Ancaman yang mungkin timbul dipengaruhi oleh ada potensi hubungan dengan pelanggan menjadi lebih buruk. 


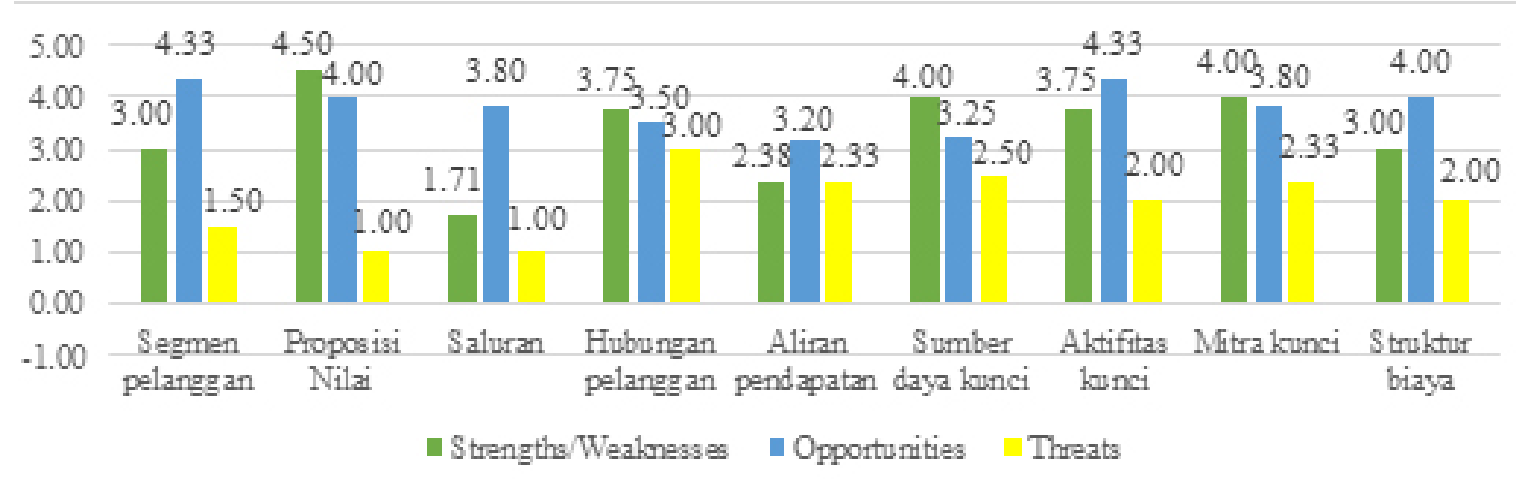

Gambar 3. Grafik hasil evaluasi SWOT pada 9 elemen model bisnis PT. XYZ

\section{Revenue streams}

Hasil penilaian pada elemen aliran pendapatan adalah kekuatan/kelemahan 2,38 (sedang), peluang 3,2 (sedang), dan ancaman 2,33 (rendah). Kekuatan aliran pendapatan dipengaruhi oleh pendapatan berulang yang berkelanjutan. Dengan data perkiraan dari pelanggan, PT. XYZ mampu memperkirakan pendapatan. Peluang yang berpengaruh adalah pendapatan dengan transaksi berulang. Ancaman elemen aliran pendapatan adalah ketergantungan terhadap satu atau lebih sumber pendapatan sehingga diperlukan langkah untuk meningkatkan aliran pendapatan untuk minimalisasi risiko menurunnya pendapatan.

\section{Key resources}

Hasil penilaian pada elemen sumber daya kunci adalah kekuatan/kelemahan 4,00 (tinggi), peluang 3,25 (sedang), dan ancaman 2,50 (sedang). Kekuatan sumber daya kunci dipengaruhi oleh kemampuan mengelola sumber daya yang sulit ditiru oleh pesaing sehingga mampu diprediksi dengan jumlah yang tepat. Peluang untuk menggunakan sumber daya yang lebih murah menjadi hal yang harus dipertimbangkan. Ancaman yang timbul adalah gangguan dalam pasokan sumber daya serta kualitas.

\section{Key activities}

Hasil penilaian pada elemen aktivitas kunci adalah kekuatan/kelemahan 3,75 (tinggi), peluang 4,33 (tinggi), dan ancaman 2,00 (rendah). Kekuatan aktivitas kunci dipengaruhi oleh aktivitas kunci yang dilakukan secara efisien dan kualitas dari aktivitas yang baik. Peluang yang berpengaruh adalah standardisasi beberapa aktivitas serta penggunaan teknologi secara maksimal. Ancaman menurunnya kualitas aktivitas menjadi faktor yang perlu dipertimbangkan.

\section{Key partners}

Hasil penilaian pada elemen mitra kunci adalah kekuatan/kelemahan 4,00 (tinggi), peluang 3,80(tinggi), dan ancaman 2,33 (rendah). Kekuatan mitra kunci dipengaruhi oleh hubungan kerja yang baik dan fokus terhadap mitra. Peluang outsourcing dan membangun kerjasama yang lebih kuat untuk meningkatkan fokus terhadap usaha inti. Ancaman yang muncul adalah mitra dapat berkolaborasi dengan pesaing.

\section{Cost structure}

Hasil penilaian pada elemen struktur biaya adalah kekuatan/kelemahan 3,00 (sedang), peluang 4,00 (tinggi), dan ancaman 2,00 (rendah). Kekuatan struktur biaya dipengaruhi oleh kemampuan dalam memperkirakan struktur biaya serta biaya yang timbul selaras dengan model bisnis yang diaplikasikan. Kemampuan dalam membatasi biaya merupakan peluang yang harus diperhatikan. Biaya yang cenderung tidak dapat diperkirakan serta yang tumbuh lebih cepat dari pendapatan merupakan ancaman yang harus diantisipasi.

\section{Pengembangan Model Bisnis I}

Gambar 4 adalah pengembangan model bisnis I. Desain pengembangan model bisnis dilakukan dengan metode kombinasi kanvas model bisnis dengan strategi samudra biru (Blue Ocean Strategy). Kaidah ERRC (Eliminate, Reduce, Raise and Create) (Kim dan 
Mauborgne, 2005) digunakan untuk memudahkan analisis pengembangan. Pengembangan model bisnis ini dilakukan pada elemen struktur biaya. Hal ini selaras dengan arah pengembangan perusahaan dengan melakukan perbaikan pada elemen biaya. Layaknya sebuah visi pada perusahaan, arah pengembangan menjadi kerangka kerja yang mampu memberikan petunjuk menuju masa depan (Ayodele, 2011).

Pada blok key partners, menciptakan komponen baru mitra kunci, yaitu menjalin kerja sama dengan pemasok lokal. Hal ini akan berdampak pada berkurangnya pembelian dari pemasok luar negeri. Hal ini dilakukan karena harga material relatif lebih murah namun memiliki kualitas produk yang sama sehingga memungkinkan menurunkan biaya pembelian bahan baku. Perubahan pada blok key activites berdampak perubahan pada elemen value propositions dimana terciptanya harga jual material baja yang lebih murah akibat berkurangnya biaya pembelian material melalui pemasok lokal.

Direct channels merupakan komponen pada blok channels yang harus ditingkatkan dengan tujuan lebih menyerap berbagai informasi dari pelanggan dan memperkuat penyampaian informasi nilai dari produk perusahaan terutama produk yang berasal dari pemasok lokal. Blok customer segments menjadi sangat berpotensi untuk dikembangkan. Perluasan pasar semakin memungkinkan untuk dilakukan. Dengan demikian, peningkatan penjualan dapat diwujudkan. Pendapatan PT. XYZ sangat memungkinakn ditingkatkan. Hal ini dapat diwujudkan dari aktivitas pembelian bahan baku melalui pemasok lokal dan perluasan pasar yang berdampak pada pengurangan biaya akan memberikan dampak perbaikan pada blok revenue streams, yaitu bertambahnya pendapatan.

\section{Pengembangan Model Bisnis II}

Gambar 5 adalah pengembangan model bisnis II dimana blok key partners mengalami perubahan melalui penciptaan komponen pada blok key activities yaitu pengembangan sistem operasi bisnis. Hal ini berdampak pada terciptanya komponen pada blok key partners, yaitu konsultan TI yang berfungsi dalam meelakukan pengembangan dan perawatan sistem operasi bisnis. Hal lain yang terjadi sebagai dampak dari perubahan blok key activities adalah munculnya komponen baru, yaitu sistem operasi bisnis pada blok key resources.

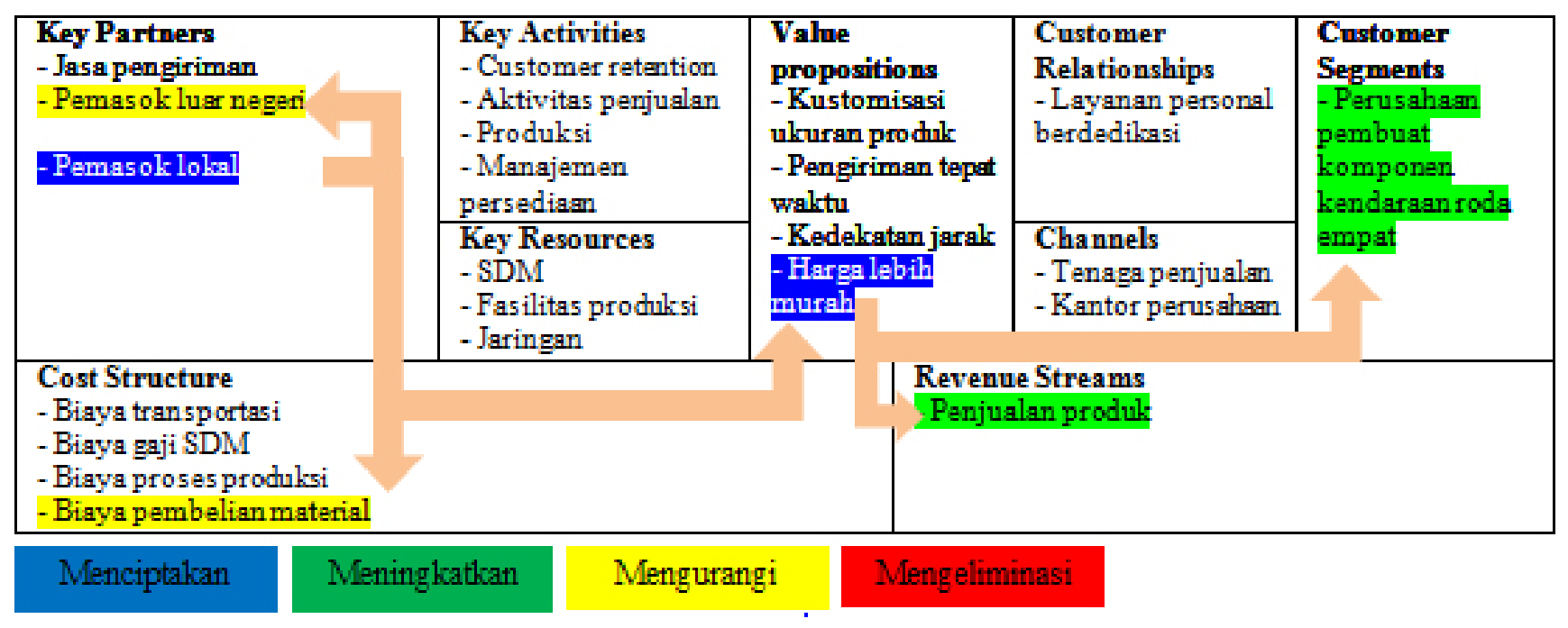

Gambar 4. Pengembangan model bisnis I PT. XYZ 


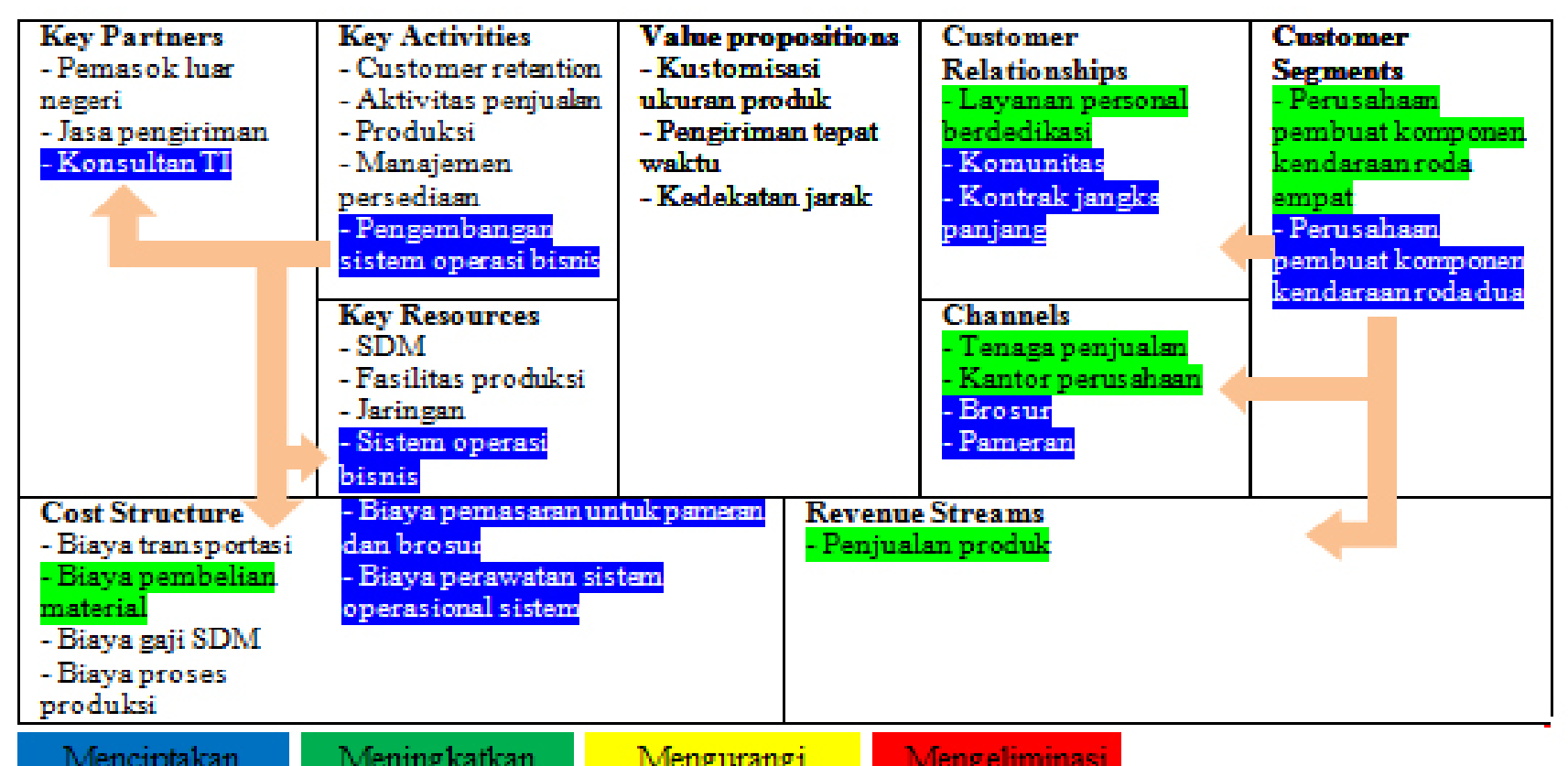

Gambar 5. Pengembangan model bisnis II PT. XYZ

Pada blok customer relationships perlu dilakukan peningkatan layanan bantuan personal yang berdedikasi. Hal ini sangat perlu dilakukan mengingat pengembangan pada blok customer segment yang sangat memerlukan komunikasi lebih intensif dengan calon pelanggan baru yaitu perusahaan pembuat komponen dua roda. Berdasarkan hasil analisis SWOT, blok customer relationships memiliki nilai ancaman 3,00 (sedang) dimana dipengaruhi adanya potensi hubungan dengan pelanggan yang menjadi lebih buruk. Untuk menghindari kondisi tersebut, PT. XYZ berupaya menciptakan komunitas bagi pelanggan. Hal ini menjadi media komunikasi antar pelanggan dengan pemasok. PT. XYZ juga berupaya untuk menciptakan hubungan kontrak jangka panjang untuk memastikan hubungan bisnis dalam waktu jangka panjang.

Blok channels perlu dikembangkan dalam rangka memperkenalkan produk dan layanan kepada calon pelanggan dengan jangkauan area yang lebih luas. Pembuatan brosur sangat berguna untuk menyampaikan informasi produk dan layanan dengan cepat. PT. XYZ pun perlu turut serta dalam acara pameran yang terkait dengan industri manufaktur untuk menjaring calon pelanggan yang berasal dari segmen yang lebih luas yaitu perusahaan pembuat komponen dua roda. Secara bersamaan, tenaga penjualan dan kantor perusahaan perlu diperhatikan dan diperbaiki untuk meningkatkan kualitas.
Selaras dengan perubahan yang terjadi pada blok customer segment, channels, dan customer relationships, perubahan pun terjadi pada blok lain, yaitu customer streams. Terciptanya komponen baru pada blok customer segment memberikan peluang besar pada peningkatan aliran pendapatan. Adanya perubahan blok key activities menyebabkan perubahan pada blok cost structure. Aktivitas pengembangan sistem operasi bisnis menimbulkan biaya baru untuk keperluan pengembangan dan perawatan sistem tersebut. Perubahan blok channels pun berpengaruh terhadap cost structure. Biaya pemasaran untuk pembuatan brosur dan biaya untuk mengikuti kegiatan pameran merupakan komponen baru yang muncul pada blok cost structure. Selain itu, biaya pembelian bahan baku menjadi komponen yang mengalami peningkatan seiring meningkatnya jumlah pembelian bahan baku akibat komponen baru pada blok customer segment yaitu otomotif 2 roda.

\section{Implikasi Manajerial}

Penelitian ini dilakukan untukmenyusun pengembangan bisnis baja PT. XYZ dengan mengacu pada business model canvas dan blue ocean strategy. Pengembangan bisnis I fokus pada struktur biaya yang dimiliki PT. XYZ yang menjadi acuan bagi perusahaan untuk mengembangkan bisnis. Strategi mengurangi biaya adalah langkah yang harus ditempuh melalui pembelian dari pemasok lokal dan mengurangi pembelian dari 
pemasok luar negeri. Hal ini memiliki implikasi pada efisiensi pengeluaran biaya. Pengembangan bisnis II fokus pada sistem operasi bisnis yang mampu menunjang aktivitas perusahaan dan diperlukannya kerjasama mitra konsultan TI. Pun segmen pelanggan perlu diperbaiki untuk meningkatkan penjualan dengan menyasar perusahaan pembuat komponen dua roda. Kedua hal tersebut akan memberikan dampak pada efisiensi jam kerja dan beban kerja karyawan serta peningkatan penjualan.

\section{KESIMPULAN DAN SARAN}

\section{Kesimpulan}

Identifikasi model bisnis PT. XYZ dengan pendekatan Business Model Canvas berhasil dilakukan. Perusahaan pembuat komponen kendaraan roda 4 merupakan komponen elemen customer segments. Komponen Value propositions adalah penyedia bahan baku baja dengan kustomisasi ukuran, pengiriman tepat waktu, dan lokasi dengan jarak terjangkau. Channels yang diterapkan adalah proses transaksi penjualan produk secara langsung kepada pelanggan. Customer relationship yang dijalankan adalah hubungan yang bersifat dedicated personal assistance (bantuan personal yang berdedikasi). Revenue streams yang didapatkan perusahaan merupakan hasil dari penjualan material baja (asset sale). Key activities perusahaan meliputi sales activity, customer retention, production, dan inventory management. Key resources yang diperlukan perusahaan adalah sumber daya manusia, fasilitas fisik, dan jaringan. Key partners perusahaan yaitu perusahaan pemasok baja dari luar negeri dan perusahaan jasa pengiriman. Komponen Cost structure adalah biaya transportasi, biaya pembelian material, biaya tenaga kerja, dan biaya produksi.

Model bisnis PT. XYZ dipengaruhi oleh faktor internal yang dibedakan ke dalam 4 hal 1) product, yang dipengaruhi oleh bahan baku, kualitas, sumber daya manusia, dan proses produksi, 2) customer interface, yang dipengaruhi oleh kedekatan hubungan dan jarak, 3) Infrastructure management yang dipengaruhi oleh keterampilan, motivasi, dan sistem imbalan bagi sumber daya manusia, 4) Financial aspect, yang dipengaruhi oleh hubungan yang baik dengan penanam modal. Selain faktor internal, model bisnis perusahaan dipengaruhi oleh faktor eksternal secara berturut-turut yaitu kekuatan pasar, kekuatan industri, tren kunci, dan kekuatan ekonomi makro. Analisis pengembangan model bisnis dilakukan analisi SWOT 9 elemen model bisnis yang menunjukkan faktor kekuatan dan kelemahan utama dengan nilai tertinggi pada elemen value propositions dan nilai terendah pada elemen channels. Peluang dengan nilai tertinggi ada pada elemen customer segments dan key activities, peluang dengan nilai terendah ada pada elemen revenue streams. Nilai tertinggi faktor ancaman terdapat pada elemen customer relationship dan nilai terendahnya ada pada elemen value proposition dan channels.

Strategi pengembangan model bisnis dilakukan dengan menerapkan perspektif blue ocean strategy. Terdapat dua strategi pengembangan. Strategi pertama fokus pada elemen cost structure yaitu mengurangi pembelian bahan baku secara impor dan menciptakan komponen pemasok lokal pada elemen key partners. Strategi pengembangan kedua fokus pada elemen key activities dan customer segments. Pengembangan key activities dilakukan dengan pengembangan TI yaitu pengembangan sistem operasi bisnis. Pengembangan customer segments dilakukan dengan dengan menyasar perusahaan pembuat komponen kendaraan roda doa.

\section{Saran}

Perlunya dilakukan penelitian terkait bisnis kemitraan sebagai bentuk pengembangan elemen key partners yang bertujuan untuk pengembangan value propositions karena memungkinkan bertambahnya varian produk. Saran berikutnya adalah melakukan evaluasi dari setiap aktivitas operasi bisnis perusahaan secara berkelanjutan dan berkala sebagai bentuk pengendalian proses terhadap target.

\section{DAFTAR PUSTAKA}

Amit R, Zott C. 2012. Creating value through business model innovation. MITSloan Management 53(3):37-44.

Ati L, Baga LM, Satria A. 2019. Business model canvas non government organization (NGO) (Case Study: Rimbawan Muda Indonesia). Indonesian Journal of Business and Entrepreneurship 5(1):32-43. https://doi.org/10.17358/ijbe.5.1.32.

Auguar, Firdaus M, Sahara. 2017. Pengembangan Strategi PT ABC niaga di industri distribusi gas. 
Jurnal Aplikasi Bisnis dan Manajemen 3(3): 373383. https://doi.org/10.17358/jabm.3.3.373.

Ayodele IO. 2011. The role of strategic vision process in business development in Nigeria. Global Journal of Management and Business Research 11(9):16-22.

Baden-Fuller C, Morgan MS. 2010. Business models as models. Journal of Long Range Planning 43(2): 156-171. https://doi.org/10.1016/j. lrp.2010.02.005.

Bamford CE, Dean TJ, Mcdougall PP. 2000. An examination of the impact of initial founding conditions and decisions upon the performance of new banks start-ups. Journal of Business Venturing 15(3): 253-277. https://doi. org/10.1016/S0883-9026(98)00011-1.

Boedianto LP, Harjanti D. 2015. Strategi pengembangan bisnis pada depot selaris dengan pendekatan business model canvas. Agora 3(2): 292-301.

Brandenburger AM, Nalebuff BJ. 1995. The Right Game: Use Game Theory To Shape Strategy. Harvard Business Review 76: 57-71.

Brandenburger AM, Stuart HW. 1996. Value-based business strategy. Journal of economics \& management strategy 5(1): 5-24. https://doi. org/10.1111/j.1430-9134.1996.00005.x.

Dewi NR, Sukardi, Djohar S. 2018. Formulasi strategi pengembangan bisnis salon XYZ. Jurnal Aplikasi Bisnis dan Manajemen 4(3): 365-376. https://doi.org/10.17358/jabm.4.3.365.

Fathurohman F. 2018. Model bisnis kawasan peternakan Kabupaten Subang. Jurnal Ilmiah Ilmu dan Teknologi Rekayasa 1(1): 36-45. https://doi. org/10.31962/jiitr.v1i1.1.

Giesen E, Berman SJ, Bell R, Blitz A. 2007. Three ways to successfully innovate your business model. Strategy \& leadership 35(6): 27-33. https://doi. org/10.1108/10878570710833732.

Hasni, Manulang H. 2011. Peranan sektor baja dalam perekonomian Indonesia. Buletin Ilmiah Litbang Perdagangan 5(1): 22-46.

[IISIA] Indonesia Iron And Steel Industry Association. 2017. Indonesia steel industry : development \& opportunities. https://www.oecd.org/industry/ ind/Item_9_5_Indonesia.pdf [2018 Nov 28].

Ishlah T. 2009. Potensi bijih besi Indonesia dalam kerangka pengembangan klaster industri baja. Buletin Sumber Daya Geologi 4(2): 12-21.

[Kemenperin] Kementrian Perindustrian Republik Indonesia. 2015. Rencana Induk Pembangunan
Industri Nasional 2015-2035. http://kemenperin. go.id/ripin.pdf [2018 Nov 28].

Kim WC, Mauborgne R. 2005. Blue Ocean Strategy: How to Create Uncontested Market Space and Make the Competition Irrelevant. Boston: Harvard Business School Press.

Osterwalder A, Pigneur Y. 2010. Business Model Generation. New Jersey: John Wiley \& Sons, Inc.

[Perpres] Peraturan Presiden. 2008. Kebijakan Industri Nasional. Jakarta: Presiden Republik Indonesia.

Prasetyo E. 2010. Struktur dan kinerja industri besi dan baja Indonesia tidak sekuat dan sekokoh namanya. Jurnal Ekonomi dan Kebijakan 3(1): $12-27$.

Puryani, Baga LM, Saptono IT. 2019. Formulasi strategi bisnis perusahaan original equipment manufacturer (OEM) Studi Kasus di PT XYZ. Jurnal Aplikasi Bisnis dan Manajemen 5(1): 13 23. https://doi.org/10.17358/jabm.5.1.13.

Rangkuti F. 2006. Analisis SWOT Teknik Membedah Kasus Bisnis. Jakarta: Gramedia.

[SEAISI] South East Asia Iron and Steel Institute. 2017. Performance of the ASEAN Iron and Steel Industryin2017 andOutlook.http://seaisi.org/file/ Performance $\% 20$ of $\% 20$ the $\% 20$ ASEAN $\% 20$ Iron $\% 20$ and $\% 20$ Steel $\% 20$ Industry $\% 20 \mathrm{in} \% 20$ 2017\%20and\%20Outlook_2018.pdf [2018 Nov $28]$.

Shafera SM, Smitha HJ, Linderb JC. 2005. The power of business models. Business Horizons 48(3). 199-207. https://doi.org/10.1016/j. bushor.2004.10.014.

Stefan S, Richard B. 2014. Analysis of business models. Journal of Competitiveness 6(4): 19-40. https:// doi.org/10.7441/joc.2014.04.02.

Tarigan CA, Machfud, Safari A. 2019. Pengembangan produk baru untuk mendukung strategi bisnis perusahaan mineral industrial (studi kasus: PT. XYZ). Jurnal Aplikasi Bisnis dan Manajemen 5(3): 397-409. https://doi.org/10.17358/ jabm.5.3.397.

Teece DJ. 2010. Business models, business strategy and innovation. Long Range Planning 43(2-3): 172 194.https://doi.org/10.1016/j.lrp.2009.07.003.

Wrigley C, Straker K. 2016. Designing innovative business models with a framework that promotes experimentation. Strategy \& Leadership 44(1): 9-11. https://doi.org/10.1108/SL-06-2015-0048. Manalu DST. 2018. Strategi pengembangan bisnis 
badan usaha milik petani (BUMP) PT. Padi Energi Proklamasi Di Kabupaten Karawang, Jawa Barat. MAHATANI: Jurnal Agribisnis 1(1):1-17.

Yoga IWFA, Wrasiati LP, Putra GPG. Strategi pengembangan usaha air minum dalam kemasan (studi kasus PT. Govinda Tirta, Nyanglan Bangli). Jurnal Rekayasa Dan Manajemen 4(4): 12-23.
Zakaria A, Aditiawati P, Rosmiati M. 2018. Strategi pengembangan usahatani kopi arabika (kasus pada petani kopi di Desa Suntenjaya Kecamatan Lembang Kabupaten Bandung Barat, Provinsi Jawa Barat). Jurnal Sosioteknologi 16(3): 325-339. https://doi.org/10.5614/sostek. itbj.2017.16.3.7. 